\title{
Comparative Studies on the Biology and Filarial Susceptibility of Selected Blood-feeding and Autogenous Aedes togoi Sub-colonies
}

\author{
Anuluck Junkum, Wej Choochote/ ${ }^{+}$, Atchariya Jitpakdi, Somjai Leemingsawat**, \\ Narumon Komalamisra**, Narissara Jariyapan, Chavalit Boonyatakorn*
}

\begin{abstract}
Department of Parasitology, Faculty of Medicine *Small Animal Clinic, Faculty of Veterinary Medicine, Chiang Mai University, Chiang Mai 50200, Thailand **Department of Medical Entomology, Faculty of Tropical Medicine, Mahidol University, Bangkok, Thailand
\end{abstract}

Blood-feeding and autogenous sub-colonies were selected from a laboratory, stock colony of Aedes togoi, which was originally collected from Koh Nom Sao, Chanthaburi province, Southeast Thailand. Comparative biology and filarial susceptibility between the two sub-colonies (blood-feeding: $F_{11}, F_{13}$; autogeny: $F_{38}, F_{40}$ ) were investigated to evaluate their viability and vectorial capacity. The results of comparison on biology revealed intraspecific differences, i.e., the average egg deposition/gravid female $\left(F_{11} / F_{38} ; F_{13} / F_{40}\right)$, embryonation rate $\left(F_{13}\right)$ $\left.F_{40}\right)$, hatchability rate $\left(F_{11} / F_{38} ; F_{13} / F_{40}\right)$, egg width $\left(F_{11} / F_{38}\right)$, wing length of females $\left(F_{13} / F_{40}\right)$, and wing length and width of males $\left(F_{11} / F_{38}\right)$ in the blood-feeding sub-colony were significantly greater than that in the autogenous sub-colony; and egg length $\left(F_{11} / F_{38}\right)$ and width $\left(F_{13} / F_{40}\right)$, and mean longevity of adult females $\left(F_{11} / F_{38}\right)$ and males $\left(F_{13} / F_{40}\right)$ in the blood-feeding sub-colony were significantly less than that in the autogenous sub-colony. The results of comparison on filarial susceptibility demonstrated that both sub-colonies yielded similar susceptibilities to Brugia malayi [blood-feeding/autogeny $=56.7 \%\left(F_{11}\right) / 53.3 \%\left(F_{38}\right), 60 \%\left(F_{13}\right) / 83.3 \%\left(F_{40}\right)$ ] and Dirofilaria immitis [blood-feeding/autogeny $\left.=85.7 \%\left(F_{11}\right) / 75 \%\left(F_{38}\right), 45 \%\left(F_{13}\right) / 29.4 \%\left(F_{40}\right)\right]$, suggesting autogenous Ae. togoi subcolony was an efficient laboratory vector in study of filariasis.

Key words: Aedes togoi - blood feeding - autogeny - biology - filarial susceptibility - Brugia malayi - Dirofilaria immitis

Lymphatic filariasis, due to Brugia malayi and Wuchereria bancrofti, is still an important mosquito-borne human disease in many countries of Asia, particularly in India, Indonesia, Malaysia, the Philippines, Sri Lanka and Thailand (WHO 2001).

In order to carry out a variety of research and development concerning lymphatic filariasis, e.g., physiology, biochemistry, pharmacology, pathology, immunology and molecular biology, it is necessary to use infective larvae as a starting point of investigations. This has led to a search for a reliable laboratory vector. Consequently, Aedes togoi (Taiwan strain) has been selected and used widely for more than three decades as an efficient laboratory vector in the mass-production of infective larvae. It is easily bred and maintained in an insectarium, is a good bloodfeeder and highly susceptible to a wide range of genera and species of filariae, i.e., periodic B. malayi, subperiodic B. malayi, B. pahangi, rural strain of W. bancrofti, Dirofilaria immitis, Breinlia sp. and Setaria sp. (Ramachandran et al. 1963). An additional strain of Ae. togoi (Thailand strain) was subsequently affirmed (Choochote et al. 1983, 1987), since it was highly susceptible to the nocturnally periodic (urban strain) and subperiodic (rural strain) $W$.

${ }^{+}$Corresponding author. Fax: +66-53-217144. E-mail: wchoocho@mail.med.cmu.ac.th

Received 5 August 2002

Accepted 2 April 2003 bancrofti, nocturnally subperiodic $B$. malayi, B. pahangi and $D$. immitis. The disadvantage in both colonies of $A e$. togoi is the regular live bloodmeals necessary for routine maintenance. However, the Ae. togoi (Thailand strain) exhibited autogenous behavior (Choochote et al. 1987), and to take advantage of this, a selected autogenous subcolony was established and subsequent generations prove to be an efficient laboratory vector of filariae. This was because the 8 th and 17 th generations of the selected sub-colony yielded similar susceptibilities (to B. malayi and $D$. immitis) to the stock colony (mixed blood-feeding and autogeny) (Riyong et al. 2000). As an addition to the previous study, we report herein, the comparative biology and filarial susceptibility of the 11th and 13th generations of selected blood-feeding, and the 38th and 40th generations of selected autogenous Ae. togoi sub-colonies.

\section{MATERIALS AND METHODS}

Mosquitoes - The stock colony of Ae. togoi was obtained originally from Koh Nom Sao, Chanthaburi province, Southeast Thailand. The colony was established in the insectarium of the Department of Medical Entomology, Faculty of Tropical Medicine, Mahidol University, Bangkok, Thailand in 1981. Since 1983, it has been maintained continuously for several generations in the insectarium of the Department of Parasitology, Faculty of Medicine, Chiang Mai University, Chiang Mai, Thailand.

Establishment of blood-feeding and autogenous subcolonies - As declared by Choochote et al. (1987) and Riyong et al. (2000) and, this stock colony-strain of $A e$. togoi exhibited both blood-feeding and autogenous behavior simultaneously within the colony, thus, the selec- 
tions of sub-colonies were divided into blood-feeding and autogenous individuals. For the blood-feeding subcolony, approximately 100 egg batches of blood-fed adult females were pooled, the hatched larvae were reared to the next generation, and blood-fed adult females were allowed to oviposit egg again. This process was repeated continuously to establish the selected blood-feeding subcolony. For the selected autogenous sub-colony, the process for selection mainly followed that for the blood-feeding sub-colony, except egg batches obtained from nonblood feeding adult females were used.

Biological study - In order to determine the viability of selected blood-feeding and autogenous Ae. togoi subcolonies, comparative studies were carried out on feeding (fed on golden hamster, and for autogenous subcolony: the females that deposited first autogenous batch of eggs were used) and mating abilities by measuring the insemination rate, oviposition capacity, average egg deposition/gravid female, embryonation rate, hatchability rate, egg dimensions, wing dimensions (right wing of each adult; length: axial incision to apical margin excluding the apical fringe; width: maximal width from costa to the opposite wing margin excluding the apical fringe), and female and male adult longevity (fed on 5\% sucrose solution). To rule out the variable factors of the above experiments, thus, both sub-colonies of Ae. togoi were reared simultaneously under similar conditions; larval density (400 larvae/ 46 × 35 × $6 \mathrm{~cm}$-sized plastic tray containing 21 of deionized water); daily larva-feeding; an adult sex ratio of 200 females: 400 males in a $30 \mathrm{~cm}$ cube cage; and maintenance in an insectarium ( $12 \mathrm{~h}$ illumination, $27 \pm 2^{\circ} \mathrm{C}, 70 \pm$ $10 \% \mathrm{RH})$. The 11th and 13th generations of a selected blood-feeding sub-colony, and the 38th and 40th selected autogenous sub-colony were used in these studies.

Infection of Ae. togoi with filariae - Two species of filariae, which were represented on the sites of development in vectors, were chosen and used. They were the thoracic development of the nocturnally subperiodic $B$. malayi, and the Malpighian tube development of $D$. immitis. Five-day-old adult females of both sub-colonies $\left(\mathrm{F}_{11} / \mathrm{F}_{38}, \mathrm{~F}_{13} / \mathrm{F}_{40}\right)$ (fasted for $12 \mathrm{~h}$, and for autogenous sub-colony: the females that deposited first autogenous batch of eggs were used) were allowed to feed simultaneously on the heparinized blood of an infected cat for nocturnally subperiodic $B$. malayi $($ microfilarial density $=$ $2.10 \mathrm{mf} / \mathrm{mm}^{3}$ for $\mathrm{F}_{11} / \mathrm{F}_{38}$ and $2.55 \mathrm{mf} / \mathrm{mm}^{3}$ for $\mathrm{F}_{13} / \mathrm{F}_{40}$ ), and an infected domestic dog for $D$. immitis (microfilarial density $=3.15 \mathrm{mf} / \mathrm{mm}^{3}$ for $\mathrm{F}_{11} / \mathrm{F}_{38}$ and $1.70 \mathrm{mf} / \mathrm{mm}^{3}$ for $\mathrm{F}_{13} / \mathrm{F}_{40}$ ), using the artificial membrane feeding technique, as described by Chomcharn et al. (1980). Fourteen days after feeding, all mosquitoes were dissected in normal saline solution and examined under a dissecting microscope. The harvested infective larvae were killed with hot $70 \%$ ethanol and mounted in glycerine on a slide, and body dimensions were assessed under a compound microscope using a camera-lucida drawing.

\section{RESULTS}

Biological study - Details of comparison on some biological aspects between blood-feeding and autogenous sub-colonies are presented in Table I.
Results demonstrated that there were some intraspecific differences of the biology that were not related to the behavior of the sub-colonies. The average egg deposition/gravid female $\left[\mathrm{F}_{11} / \mathrm{F}_{38}: 190.20 \pm 39.20 / 98.27 \pm 31.81\right.$ $(\mathrm{t}=9.97, \mathrm{p}<0.05), \mathrm{F}_{13} / \mathrm{F}_{40}: 115.24 \pm 32.46 / 85.31 \pm 21.99$ $(\mathrm{t}=4.11, \mathrm{p}<0.05)]$, embryonation rate $\left[\mathrm{F}_{13} / \mathrm{F}_{40}: 99.33 /\right.$ $\left.77.33\left(\chi^{2}=70.45, \mathrm{p}<0.05\right)\right]$, hatchability rate $\left[\mathrm{F}_{11} / \mathrm{F}_{38}\right.$ : 94.67/89.33 $\left(\chi^{2}=5.80, \mathrm{p}<0.05\right), \mathrm{F}_{13} / \mathrm{F}_{40}: 91.00 / 74.00\left(\chi^{28}=\right.$ $30.03, \mathrm{p}<0.05)]$, egg width $\left[\mathrm{F}_{11} / \mathrm{F}_{38}: 197.22 \pm 9.52 \mu \mathrm{m} /\right.$ $190.93 \pm 11.07 \mu \mathrm{m}(\mathrm{t}=2.36, \mathrm{p}<0.05)]$, wing length of females $\left[\mathrm{F}_{13} / \mathrm{F}_{40}: 3.29 \pm 0.10 \mathrm{~mm} / 3.23 \pm 0.08 \mathrm{~mm}(\mathrm{t}=2.46\right.$, $\mathrm{p}<0.05)]$, and wing length and width of males $\left[\mathrm{F}_{11} / \mathrm{F}_{38}\right.$ : length $2.69 \pm 0.05 \mathrm{~mm} / 2.65 \pm 0.04 \mathrm{~mm}(\mathrm{t}=3.48, \mathrm{p}<0.05)$, width $0.71 \pm 0.01 \mathrm{~mm} / 0.69 \pm 0.02 \mathrm{~mm}(\mathrm{t}=3.01, \mathrm{p}<0.05)]$ in the blood-feeding sub-colony were significantly greater than that in the autogenous sub-colony, whereas the egg length and width $\left[\mathrm{F}_{11} / \mathrm{F}_{38}\right.$ : length $553.88 \pm 19.92 \mu \mathrm{m} / 565.78$ $\pm 21.70 \mu \mathrm{m}(\mathrm{t}=2.21, \mathrm{p}<0.05), \mathrm{F}_{13} / \mathrm{F}_{40}$ : width $179.83 \pm 10.09$ $\mu \mathrm{m} / 186.43 \pm 11.01 \mu \mathrm{m}(\mathrm{t}=3.86, \mathrm{p}<0.05)]$, and mean longevity of adult females and males $\left[\mathrm{F}_{11} / \mathrm{F}_{38}\right.$ : female $27.33 \pm$ 13.97 day $/ 35.97 \pm 15.06$ day, $\mathrm{F}_{13} / \mathrm{F}_{40}$ : male $29.17 \pm 11.63$ day $/ 45.70 \pm 12.18$ day $(\mathrm{t}=5.38, \mathrm{p}<0.05)]$ in the bloodfeeding sub-colony were significantly less than that in the autogenous sub-colony.

Filarial susceptibility - Details of infective rates and parasite loads in selected blood-feeding and autogenous Ae. togoi sub-colonies are shown in Table II.

For B. malayi, the dissection results of all infected mosquitoes on day 14 demonstrated that the selected blood-feeding and autogenous sub-colonies yielded similar filarial susceptibilities $\left[\mathrm{F}_{11} / \mathrm{F}_{38}: 56.67 / 53.33\left(\chi^{2}=0.07\right.\right.$, $\left.\mathrm{p}>0.05), \mathrm{F}_{13} / \mathrm{F}_{40}: 60.00 / 83.33\left(\chi^{2}=2.95, \mathrm{p}>0.05\right)\right]$ and an average number of infective larvae/infected mosquito $\left[\mathrm{F}_{11} / \mathrm{F}_{38}: 5.82(1-29) / 3.75(1-22)(\mathrm{t}=0.89, \mathrm{p}>0.05), \mathrm{F}_{13} /\right.$ $\left.\mathrm{F}_{40}: 11.38(1-54) / 17.76(1-51)(\mathrm{t}=1.27, \mathrm{p}>0.05)\right]$. The infective larvae obtained from all experimental feedings were very active and found to be distributed in all regions, but they were mainly located on the head and proboscis, where more than $70 \%$ of infective larvae could be observed. Nonetheless, intraspecific differences in the body dimensions of infective larvae that were also found from the blood-feeding sub-colony, i.e., $\mathrm{F}_{11} / \mathrm{F}_{38}$ : body length $1633.50 \pm 101.26 \mu \mathrm{m} / 1552.83 \pm 142.02 \mu \mathrm{m}(\mathrm{t}=2.53, \mathrm{p}<0.05)$ and body width $25.56 \pm 1.50 \mu \mathrm{m} / 24.70 \pm 1.47 \mu \mathrm{m}(\mathrm{t}=2.23$, $\mathrm{p}<0.05$ ) were significantly larger than that in the autogenous sub-colony, and the $\mathrm{F}_{13} / \mathrm{F}_{40}$ : body length 1544.43 $\pm 143.28 \mu \mathrm{m} / 1616.65 \pm 111.44 \mu \mathrm{m}(\mathrm{t}=2.18, \mathrm{p}<0.05)$ obtained from the blood-feeding sub-colony was significantly smaller than that in the autogenous sub-colony.

For D. immitis, both sub-colonies yielded the same filarial susceptibilities $\left[\mathrm{F}_{11} / \mathrm{F}_{38}: 85.71 / 75.00\right.$ (Fisher exact $\left.\mathrm{p}>0.05), \mathrm{F}_{13} / \mathrm{F}_{40}: 45.00 / 29.41\left(\chi^{2}=0.95, \mathrm{p}>0.05\right)\right]$, with an average number of infective larvae/infected mosquitoes $\left[\mathrm{F}_{11} / \mathrm{F}_{38}: 8.00(1-21) / 6.78(1-23)(\mathrm{t}=0.57, \mathrm{p}>0.05)\right.$, $\left.\mathrm{F}_{13} / \mathrm{F}_{40}: 14.44(2-48) / 11.40(1-35)(\mathrm{t}=0.37, \mathrm{p}>0.05)\right]$. More than $65 \%$ of infective larvae could migrate to the head and proboscis, except in the $\mathrm{F}_{13}$ experiment where only $36.15 \%$ of infective larvae could migrate to the head and proboscis, and as much as $53.1 \%$ of them were found in the abdomen. Nevertheless, body width $23.18 \pm 1.23 \mu \mathrm{m}$ $\left(\mathrm{F}_{13}\right) / 23.85 \pm 1.02 \mu \mathrm{m}\left(\mathrm{F}_{40}\right)(\mathrm{t}=2.31, \mathrm{p}<0.05)$ recovered 
TABLE I

Comparative biology of the selected blood-feeding and autogenous Aedes togoi sub-colonies

\begin{tabular}{|c|c|c|c|c|}
\hline & \multicolumn{2}{|c|}{ Experiment 1} & \multicolumn{2}{|c|}{ Experiment 2} \\
\hline & $\mathrm{SB}\left(\mathrm{F}_{11}\right)$ & $\mathrm{SA}\left(\mathrm{F}_{38}\right)$ & $\mathrm{SB}\left(\mathrm{F}_{13}\right)$ & $\mathrm{SA}\left(\mathrm{F}_{40}\right)$ \\
\hline Feeding rate (No.) & $92.50(37 / 40)$ & $95.00(38 / 40)$ & $85.00(34 / 40)$ & $80.00(32 / 40)$ \\
\hline Insemination rate (No.) & $100(30 / 30)$ & $100(30 / 30)$ & $93.33(28 / 30)$ & $100(30 / 30)$ \\
\hline Oviposition rate (No.) & $96.67(29 / 30)$ & $86.67(26 / 30)$ & $96.67(29 / 30)$ & $96.67(29 / 30)$ \\
\hline $\begin{array}{l}\text { Average egg deposition per gravid } \\
\text { female (range) }\end{array}$ & $\begin{array}{l}190.20 \pm 39.20 \\
(20-236)\end{array}$ & $\begin{array}{l}98.27 \pm 31.81 \\
(3-129)\end{array}$ & $\begin{array}{l}115.24 \pm 32.46 \\
(63-192)\end{array}$ & $\begin{array}{l}85.31 \pm 21.99 \\
(37-116)\end{array}$ \\
\hline Embryonation rate (No.) & $97.00(291 / 300)$ & $98.67(296 / 300)$ & $99.33(298 / 300)$ & $77.33(232 / 300)$ \\
\hline Hatchability rate (No.) & $94.67(284 / 300)$ & $89.33(268 / 300)$ & $91.00(273 / 300)$ & $74.00(222 / 300)$ \\
\hline \multicolumn{5}{|l|}{ Egg dimensions $(\mu \mathrm{m})^{a}($ range $)$} \\
\hline $\begin{array}{l}\text { Length } \\
\text { Width }\end{array}$ & $\begin{array}{c}553.88 \pm 19.92 \\
(509.25-609.00) \\
197.22 \pm 9.52 \\
(178.50-220.50)\end{array}$ & $\begin{array}{c}565.78 \pm 21.70 \\
(525.00-609.00) \\
190.93 \pm 11.07 \\
(168.00-215.25)\end{array}$ & $\begin{array}{c}564.99 \pm 34.55 \\
(506.15-650.17) \\
179.83 \pm 10.09 \\
(160.49-205.75)\end{array}$ & $\begin{array}{c}565.69 \pm 24.31 \\
(484.88-593.56 \\
186.43 \pm 11.01 \\
(167.20-209.00)\end{array}$ \\
\hline \multicolumn{5}{|l|}{ Wing dimensions $(\mu \mathrm{m})^{b}$ (range) } \\
\hline $\begin{array}{l}\text { Length } \\
\text { Width }\end{array}$ & $\begin{array}{c}3.40 \pm 0.07 \\
(3.28-3.55) \\
1.04 \pm 0.02 \\
(1.00-1.08)\end{array}$ & $\begin{array}{c}3.38 \pm 0.07 \\
(3.18-3.52) \\
1.05 \pm 0.03 \\
(0.99-1.10)\end{array}$ & $\begin{array}{c}3.29 \pm 0.10 \\
(3.08-3.49) \\
1.02 \pm 0.03 \\
(0.97-1.07)\end{array}$ & $\begin{array}{c}3.23 \pm 0.08 \\
(3.07-3.45) \\
1.01 \pm 0.03 \\
(0.94-1.07)\end{array}$ \\
\hline \multicolumn{5}{|l|}{ Male } \\
\hline $\begin{array}{l}\text { Length } \\
\text { Width }\end{array}$ & $\begin{array}{c}2.69 \pm 0.05 \\
(2.61-2.80) \\
0.71 \pm 0.01 \\
(0.68-0.75)\end{array}$ & $\begin{array}{c}2.65 \pm 0.04 \\
(2.55-2.74) \\
0.69 \pm 0.02 \\
(0.66-0.74)\end{array}$ & $\begin{array}{c}2.61 \pm 0.06 \\
(2.50-2.72) \\
0.69 \pm 0.03 \\
(0.60-0.73)\end{array}$ & $\begin{array}{c}2.60 \pm 0.05 \\
(2.48-2.71) \\
0.68 \pm 0.02 \\
(0.66-0.70)\end{array}$ \\
\hline \multicolumn{5}{|c|}{ Mean longevity of adult in days (range) ${ }^{c}$} \\
\hline Female & $\begin{array}{l}27.33 \pm 13.97 \\
\quad(5-59)\end{array}$ & $\begin{array}{l}35.97 \pm 15.06 \\
\quad(5-67)\end{array}$ & $\begin{array}{l}34.23 \pm 6.12 \\
(23-43)\end{array}$ & $\begin{array}{l}35.90 \pm 13.06 \\
\quad(10-59)\end{array}$ \\
\hline Male & $\begin{array}{l}36.63 \pm 16.61 \\
\quad(5-63)\end{array}$ & $\begin{array}{l}43.03 \pm 15.20 \\
(14-69)\end{array}$ & $\begin{array}{l}29.17 \pm 11.63 \\
(9-43)\end{array}$ & $\begin{array}{l}45.70 \pm 12.18 \\
(14-64)\end{array}$ \\
\hline
\end{tabular}

$a$ : measurement from 30 eggs; $b$ : measurement from 30 wings; $c$ : observation from 30 adults; $\mathrm{SB}$ : selected blood-feeding sub-colony; SA: selected autogenous sub-colony; F: generation

from the blood-feeding sub-colony was significantly smaller than that in the autogenous sub-colony.

\section{DISCUSSION}

Extensive, comparative studies of autogenous and anautogenous mosquitoes have been reported in several species comprising at least 15 mosquito genera (Eberle \& Reisen 1986, Reisen \& Milby 1987, Clements 1992, Chambers \& Klowden 1994, Su \& Mulla 1997, Sawabe \& Moribayashi 2000, Olejnicek \& Gelbic 2000). Studies are mostly concerned with the intrinsic and extrinsic factors that influence the biology, physiology, biochemistry, mechanism and/or genetic control of autogeny, etc. Except in the study of Trpis (1981), very few studies related the autogeny of the host to parasite infection. The author reported high susceptibility in the autogenous group of the Ae. scutellaris complex (Ae. cooki, Ae. kesseli, Ae. tongae tabu and an undescribed Aedes sp.) to B. malayi and $B$. pahangi, and it was proposed that this sibling species group could serve as an excellent mosquito labo- ratory model in the study of filariasis. However, no account confirmed the susceptibility comparison of subsequent generations of consecutively selected autogenous sub-colony to both filarial species.

The results of comparative studies on some biological aspects between the selected blood-feeding and autogenous Ae. togoi sub-colonies revealed that the viability of the selected autogenous sub-colony was obviously stable up to the 40th generation, although, there were some intraspecific differences in the average egg deposition/gravid female, embryonation rate, hatchability rate, egg length and width, wing length and width, and mean longevity of adults. The marked reduction of average egg deposition/gravid female in the selected autogenous subcolony was similar to that in previous reports of autogenous Ae. togoi (Malaysia strain) (Thomas \& Leng 1972) and Culex tarsalis (Su \& Mulla 1997). The lower egg deposition/gravid female, embryonation rate and hatchability rate of autogenous sub-colony than selected blood-feeding sub-colony were the biological disadvantages of au- 
TABLE II

The infective rates and parasite loads in selected blood-feeding and autogenous Aedes togoi sub-colonies after artificial feeding on blood infected with Brugia malayi and Dirofilaria immitis, all dissected 14 days after feeding

\begin{tabular}{|c|c|c|c|c|}
\hline & \multicolumn{2}{|c|}{ Experiment 1} & \multicolumn{2}{|c|}{ Experiment 2} \\
\hline & $\mathrm{SB}\left(\mathrm{F}_{11}\right)$ & $\mathrm{SA}\left(\mathrm{F}_{38}\right)$ & $\mathrm{SB}\left(\mathrm{F}_{13}\right)$ & $\mathrm{SA}\left(\mathrm{F}_{40}\right)$ \\
\hline $\begin{array}{l}\text { B. malayi } \\
\text { Infective rate (No.) }\end{array}$ & $56.67(17 / 30)$ & $53.33(16 / 30)$ & $60.00(18 / 30)$ & $83.33(25 / 30)$ \\
\hline $\begin{array}{l}\text { Average No. L3 per } \\
\text { Infected mosquito (range) }\end{array}$ & $\begin{array}{c}5.82 \\
(1-29)\end{array}$ & $\begin{array}{c}3.75 \\
(1-22)\end{array}$ & $\begin{array}{l}11.38 \\
(1-54)\end{array}$ & $\begin{array}{l}17.76 \\
(1-51)\end{array}$ \\
\hline $\begin{array}{l}\text { L3-distribution } \\
\text { \% head (No.) } \\
\% \text { thorax (No.) } \\
\text { \% abdomen (No.) } \\
\text { Total }\end{array}$ & $\begin{array}{c}77.78(77) \\
13.13(13) \\
9.01(9) \\
99\end{array}$ & $\begin{array}{c}88.33(53) \\
5.00(3) \\
6.67(4) \\
60\end{array}$ & $\begin{array}{c}74.15(152) \\
3.90(8) \\
21.95(45) \\
205\end{array}$ & $\begin{array}{c}76.18(339) \\
8.31(37) \\
15.50(69) \\
445\end{array}$ \\
\hline $\begin{array}{l}\text { L3-dimensions }(\mu \mathrm{m})^{a} \\
\text { Mean body length } \\
\text { (range) } \\
\text { Mean body width } \\
\text { (range) }\end{array}$ & $\begin{array}{c}1633.50 \pm 101.26 \\
(1320.00-1815.00) \\
25.56 \pm 1.50 \\
(21.60-28.35)\end{array}$ & $\begin{array}{c}1552.83 \pm 142.02 \\
(1265.00-1870.00) \\
24.70 \pm 1.47 \\
(21.60-27.00)\end{array}$ & $\begin{array}{c}1544.43 \pm 143.28 \\
(1166.65-1777.76) \\
24.50 \pm 1.87 \\
(21.00-28.00)\end{array}$ & $\begin{array}{c}1616.65 \pm 111.44 \\
(1333.32-1777.76) \\
24.50 \pm 1.02 \\
(22.40-26.60)\end{array}$ \\
\hline $\begin{array}{l}\text { D. immitis } \\
\text { Infective rate (No.) }\end{array}$ & $85.71(18 / 21)$ & $75.00(18 / 24)$ & $45.00(9 / 20)$ & $29.41(5 / 17)$ \\
\hline $\begin{array}{l}\text { Average No. L3 per } \\
\text { Infected mosquito (range) }\end{array}$ & $\begin{array}{l}8.00 \\
(1-21)\end{array}$ & $\begin{array}{c}6.78 \\
(1-23)\end{array}$ & $\begin{array}{l}14.44 \\
(2-48)\end{array}$ & $\begin{array}{l}11.40 \\
(1-35)\end{array}$ \\
\hline $\begin{array}{l}\text { L3-distribution } \\
\text { \% head (No.) } \\
\% \text { thorax (No.) } \\
\text { \% abdomen (No.) } \\
\text { Total }\end{array}$ & $\begin{array}{c}86.80(125) \\
5.56(8) \\
7.64(11) \\
144\end{array}$ & $\begin{array}{c}76.23(93) \\
5.74(7) \\
18.03(22) \\
122\end{array}$ & $\begin{array}{l}36.15(47) \\
10.77(14) \\
53.08(69) \\
130\end{array}$ & $\begin{array}{c}66.67(38) \\
17.54(10) \\
15.79(9) \\
57\end{array}$ \\
\hline $\begin{array}{l}\text { L3-dimensions }(\mu \mathrm{m})^{a} \\
\text { Mean body length } \\
\text { (range) } \\
\text { Mean body width } \\
\text { (range) }\end{array}$ & $\begin{array}{c}973.50 \pm 83.16 \\
(770.00-1100.00) \\
22.95 \pm 1.37 \\
(20.25-25.65)\end{array}$ & $\begin{array}{c}999.17 \pm 50.21 \\
(880.00-1100.00) \\
23.40 \pm 1.56 \\
(20.25-27.00)\end{array}$ & $\begin{array}{c}1012.95 \pm 63.06 \\
(833.33-1111.10) \\
23.18 \pm 1.23 \\
(21.60-25.65)\end{array}$ & $\begin{array}{c}999.99 \pm 69.97 \\
(833.33-1111.10) \\
23.85 \pm 1.02 \\
(21.60-25.65)\end{array}$ \\
\hline
\end{tabular}

$a$ : measurement from 30 larvae; SB: selected blood-feeding sub-colony; SA: selected autogenous sub-colony; F: generation

togenous sub-colony. Nonetheless, the above biological variations did not have an effect on the differences in filarial susceptibility (infective rate and average number of infective larvae/infected mosquito) between the two sub-colonies, suggesting that the selected autogenous Ae. togoi sub-colony was an efficient laboratory vectormodel for the study of filariasis. Additionally, the similarity in the feeding rates of the two sub-colonies supported the advantages of the selected autogenous sub-colony.

The successful establishment of the selected autogenous Ae. togoi sub-colony $\left(\mathrm{F}_{40}\right)$ that yielded satisfactory susceptibility to both thoracic (B. malayi) and Malpighian tube (D. immitis) development filariae, will contribute to the low cost and high effectiveness of the system for mass-production of infective larvae, since the utility small-space laboratory animal to provide the mosquito bloodmeal, could be completely excluded. We now propose that our laboratory could provide this selected autogenous sub-colony $\left(\mathrm{F}_{40+}\right)$ to other researchers to facilitate the study of filariasis and/or other aspects.

\section{ACKNOWLEDGEMENTS}

To Dr Piya Netrawichien, Dean of the Faculty of Medicine, Chiang Mai University, for his interest in this research, and to the Faculty Endowment Fund for financial support.

\section{REFERENCES}

Chambers GM, Klowden MJ 1994. Nutritional reserves of autogenous and anautogenous selected strains of Aedes albopictus (Diptera: Culicidae). J Med Entomol 31: 554560.

Chomcharn Y, Surathin K, Bunnag D, Sucharit S, Harinasuta T 1980. Effects of a single dose of primaquine on a Thai strain of Plasmodium falciparum. Southeast Asian J Trop Med Public Health 11: 408-409.

Choochote W, Abeyewickreme W, Sucharit S, Apiwathnasorn C, Tumrasvin W, Leemingsawat S 1983. Aedes togoi Koh Nom Sao, Chanthaburi, a laboratory vector for Brugia malayi and Brugia pahangi in Thailand. J Parasit Trop Med Assoc Thai 6: 25-31.

Choochote W, Keha P, Sukhavat K, Khamboonruang C, Sukontason K 1987. Aedes (Finlaya) togoi Theobald 1907, 
Chanthaburi strain, a laboratory vector in studies of filariasis in Thailand. Southeast Asian J Trop Med Public Health 18: $259-260$

Clements AN 1992. The biology of mosquitoes. In Development, Nutrition and Reproduction, vol. 1, Chapman and Hall, London, 509 pp.

Eberle MW, Reisen WK 1986. Studies on autogeny in Culex tarsalis: 1. Selection and genetic experiments. J Am Mosq Control Assoc 2: 38-43.

Olejnicek J, Gelbic I 2000. Autogeny in Culex pipiens quinquefasciatus Say. J Vector Ecol 25: 118-122.

Ramachandran CP, Wharton RH, Dunn FL, Kershaw WE 1963. Aedes (Finlaya) togoi Theobald, a useful laboratory vector in studies of filariasis. Ann Trop Med Parasitol 57: 443445.

Reisen WK, Milby MM 1987. Studies on autogeny in Culex tarsalis: 3. Life table attributes of autogenous and anautogenous strains under laboratory conditions. $J \mathrm{Am}$ Mosq Control Assoc 3: 619-625.

Riyong D, Choochote W, Jitpakdi A, Suvannadabba S, Leemingsawat S, Chaitong U 2000. Autogenous Aedes togoi sub-colony (Chanthaburi, Thailand strain), an efficient laboratory vector in study of filariasis. Southeast Asian J Trop Med Public Health 31: 246-251.

Sawabe K, Moribayashi A 2000. Lipid utilization for ovarian development in an autogenous mosquito, Culex pipiens molestus (Diptera: Culicidae). J Med Entomol 37: 726-731.

$\mathrm{Su}$ T, Mulla MS 1997. Selection-dependent trends of autogeny and blood feeding in an autogenous strain of Culex tarsalis (Diptera: Culicidae). J Am Mosq Control Assoc 13: 145149.

Thomas V, Leng YP 1972. The inheritance of autogeny in Aedes (Finlaya) togoi Theobald, from Malaysia and some aspects of its biology. Southeast Asian J Trop Med Public Health 3: 163-174.

Trpis M 1981. Susceptibility of the autogenous group of the Aedes scutellaris complex of mosquitoes to infection with Brugia malayi and Brugia pahangi. Tropenmed Parasitol 32: 184-188.

WHO-World Health Organization 2001. Regional Strategic Plan for Elimination of Lymphatic Filariasis, New Delhi, 30 pp. 
Filarial Susceptibility of Ae. togoi - Anuluck Junkum et al. 